\title{
Identifying Pedagogical, Technological And Organizational Barriers In Virtual Learning Environments
}

\author{
Maria Galofré \\ Academic Organization Office \\ Universitat Oberta de Catalunya \\ Barcelona, Spain \\ mgalofre@uoc.edu
}

\author{
Julià Minguillón \\ Computer Science, Multimedia and \\ Telecommunication Studies \\ Universitat Oberta de Catalunya \\ Barcelona, Spain \\ jminguillona@uoc.edu
}

\begin{abstract}
Virtual learning environments are online spaces where learners interact with other learners, teachers, resources and the environment in itself. Although technology is meant to enhance the learning process, there are important issues regarding pedagogical and organizational aspects that must be addressed. In this paper we review the barriers detected in a virtual university which exclusively uses Internet as the main channel of communication, with no face-to-face requirements except those related to final evaluation.
\end{abstract}

\section{Categories and Subject Descriptors}

K.3.1.d [Computers and Education]: Computer Uses in Education-Distance learning; K.4.2.b [Computers and Society]: Social Issues-Assistive technologies for persons with disabilities

\section{General Terms}

Human Factors

\section{Keywords}

e-learning, virtual learning environments, accessibility, usability, personalization

\section{INTRODUCTION}

The intensive use of Information and Communication Technologies such as the Internet increases the possibilities for both content searching and delivery. This new paradigm has completely changed the vision in the distance education field. Virtual learning environments (VLE) are truly learning spaces that reproduce all the elements in a classical university. Distance education has been the most suitable solution for helping people with disabilities to obtaining a degree. In this sense, e-learning may overcome the classical spatial and temporal barriers imposed by face-to-face education, helping learners with special needs to engage in higher and lifelong education on equal conditions. Any elearning initiative must take into account three dimensions: pedagogical, technological and organizational, as stated in [2]. In the pedagogical dimension, it is clear that learning is more than just providing the learners with contents available

Copyright is held by the author/owner(s).

ASSETS'08, October 13-15, 2008, Halifax, Nova Scotia, Canada. ACM 978-1-59593-976-0/08/10. through Internet. The technological dimension defines the available web-based services of the VLE. Finally, the organizational dimension describes the processes that the users of the VLE perform during the learning process. All these three dimensions must be taken into account in VLEs.

\section{E-LEARNING ENVIRONMENTS}

The Universitat Oberta de Catalunya ${ }^{1}$ is an institution emerged from the knowledge society. The mission is to provide people with training throughout their lives. The university's principal aim is to ensure that each student satisfies his/her learning needs in a VLE, gaining the maximum benefit from their own efforts. To this end, it offers intensive use of information and communications technologies (ICT), thereby enabling us to overcome the barriers imposed by time and space for offering an educational model based on personalized attention for each individual student. Each subject has a virtual classroom for teaching and learning which is the virtual meeting point for learning activities, following a student centered model. We will focus in the academic semester level [4], because it covers most of the typical interactions between the learner and the VLE. At such level, the learner's life cycle can be decomposed in Enrollment, Learning and Evaluation.

Enrollment: the learner chooses one or more subjects that he or she wants to enroll in, with the counseling of his or her tutor. The learner performs this process using a software tool integrated in the Virtual Campus, thus receiving both human and machine support. The VLE provides the learner with all the available information regarding subjects, scheduling, evaluation activities, and so.

Learning: For each subject, the learner has access to a virtual classroom which includes four basic concepts: planning, interaction, resources and evaluation. During the academic semester, the learner is supposed to follow the proposed planning, which includes a sequence of activities, some of them evaluative. Activities include readings, doing exercises and interacting with the teacher and the other learners in the spaces created for doing so (i.e. forums).

Evaluation: at the end of the academic semester, and only for some subjects, the learner must take a final evaluation activity, which is the only mandatory face-to-face activity. This process can be divided in several sub-processes which are sequentially executed: first, choosing the place and the day of each exam; second, attending the face-to-face exams;

\footnotetext{
${ }^{1}$ http://www.uoc.edu
} 
Table 1: Distribution of students with special needs.

\begin{tabular}{|l|r|}
\hline Disability & \% of students with disabilities \\
\hline Hearing impairment & $1,44 \%$ \\
Motor disability & $22,30 \%$ \\
Fine motricity & $1,44 \%$ \\
Mental health & $7,91 \%$ \\
Visual impairment & $3,60 \%$ \\
Other (but specified) & $3,60 \%$ \\
Without specification & $59,71 \%$ \\
\hline
\end{tabular}

and third, revising the process. Learners with special needs can ask for additional assistance (more time, adapted classrooms, audio support for blind people, etc.), but they follow the same evaluation process than the rest of learners.

All these processes, services and resources are related to each other, and they are influenced by pedagogical, technological and organizational decisions. Personalization techniques can be used to adapt all the elements of the learning process to the user, following an user-centered design approach [3]. As stated in [1], one of the concerns for the distance student is the perceived lack of feedback or contact with the teacher, which may lead to frustration and dropout. One of the main concerns for people with disabilities is having to explain their condition every time they need to interact with a new element in the VLE. In fact, there are some learners with disabilities that hide their condition because they can interact with the VLE as the rest of learners, and only in specific situations (like face-to-face exams) they ask for additional assistance. For permanent disabilities, this should be done during the enrollment process. For temporal situations of disability, the learner should be able to specify such situation in order to rearrange the learning and evaluation processes, if possible. An study coordinated for the Spanish government ${ }^{2}$ shows that only $0,53 \%$ of the students at state Spanish universities have a disability. At UOC, this ratio increases up to $0,96 \%$, what upholds the fact that people with disabilities prefer distance education $(p<0.01)$, similar to the $1,6 \%$ of students with disabilities in the national distance university (UNED), the former unique distance university in Spain. Declaring a disability is a complex decision, which raises complex issues regarding disability identity and needing and receiving support [5]. Students can be reluctant to declare their disability due to different reasons, from the difficulty to assume a public identity as a disabled, to the certainty that it is the university that has to be prepared to be inclusive, covering all kind of students' needs, without having to be asked for. Table 1 shows the distribution of students with special needs according to their type of disability. Students do not have the obligation to let the university know what kind of disability they have at the moment they enroll in, and most of them do not do it, indeed.

\section{CONCLUSIONS}

The conclusions that can be withdrawn from UOC experience are the following: a) Technology is understood as a positive element of support. E-learning seems to be an advantage for students with disability, because they feel in a

\footnotetext{
${ }^{2}$ http://sid.usal.es/idocs/F8/FDO20244/

LibroBlancosobreuniversidadydiscapacidad2.pdf (in Spanish).
}

more equal conditions situation than in a face to face learning. This doesn't mean that everything is perfect and that e-learning tools as we know it nowadays are the definitive answer. In their opinion, a lot of work should be done to advance in the accessibility of technological tools. b) Personalization is needed. The accessibility solutions required for each kind and grade of disability are different, so trying to obtained a model of e-learning accessible for all is practically impossible. Students with disabilities prefer a flexible environment and pedagogical methodology that could be adapted to the personal circumstances of each one of them. c) Protocols are required. The provision of the adaptations to services, resources and processes should be stipulated and known by all the agents the students have to interact with during their learning process. They express as a very bad experience the individual negotiation they have to carry out every time they have a special need, as if they were asking for a personal favor. It should be an institutional policy indicating what they deserve and how it is going to be proportioned to them.

Future plans for improving accessibility include the redefinition of an institutional policy on this field, taking into account all the stakeholders involved: university managers and government, professors, learning technologists, students and support services. We propose the maintenance of the decentralized system existing nowadays, but accompanied by the existence of an expert service with a supporting role, without directly interacting with the students. Students should only interact with their tutor (who guides the student through their learning process) and with the personalized VLE, providing them with adaptations based on user profile and helping learners to choose among the best available options.

\section{ACKNOWLEDGMENTS}

This paper has been supported by a Spanish Government grant ref. PERSONAL(ONTO) TIN2006-15107-C02-01.

\section{REFERENCES}

[1] J. Galusha. Barriers to learning in distance education. Available at http://www.emoderators.com/ ipct-j/1997/n4/galusha.html, 1997.

[2] H. Hermans, J. Manderveld, and H. Vogten. Integrated E-Learning: implications for pedagogy, technology and organization, chapter Educational Modelling Language, pages 80-99. RoutledgeFalmer, 2004.

[3] J. Kramer, S. Noronha, and J. Vergo. A user-centered design approach to personalization. Communications of the ACM, 43(8):44-48, 2000.

[4] E. Mor, M. G. Domingo, J. Minguillón, and S. Lewis. A three-level approach for analyzing user behavior in ongoing relationships. In J. A. Jacko, editor, HCI (4), volume 4553 of Lecture Notes in Computer Science, pages 971-980. Springer, 2007.

[5] J. K. Seale. E-learning and disability in higher education. Accessibility research and practice. Routledge, 2006. 